It was suggested several years ago by L. A. Orbeli from his own morphological and physiological evidence that an increase or decrease of sensitivity of receptors is due to the vegetative nervous system. This hypothesis has been checked by means of the above method.

First of all, parallel records were made in one of a series of experiments on thresholds of the darkadapted eye, of frequency of pulse, and of electrical resistance of skin to constant current during and after excitation of various organs of sense (taste and temperature receptors). It was found that decrease of thresholds of peripheral vision is almost always accompanied by acceleration of pulse and change in skin resistance. The last-mentioned two functions are well known to be controlled by the vegetative nervous system.

In another series of experiments, the olfactory receptor of subjects was stimulated by sympathomimetic (geraniol) and parasympathomimetic (thymol) olfactory agents. In the first case sensitivity of eye as well as pulse frequency underwent increase, while in the second case the effect was opposite in character.

Finally, in a third series of experiments, use was made of the so-called vegetative tests (AnshnerDanini, Abrams, Luga, and others). It is a wellknown fact that pressure exerted on the eyeball, palatum durum or the vertebra invariably causes change in pulse frequency. According to our ex. pectations, change was also noted in the sensitivity of a dark-adapted eye, the two series of changes showing parallel courses.

Thus it will be concluded that change in sensitivity of the eye is effected by the vegetative nervous system in accordance with Orbeli's hypothesis. Change in functional properties of one organ of sense caused by stimulation of another sense organ is therefore to be regarded as a senso-sensory vegetative reflex, which in its turn is part of a diffuse reflex of the vegetative nervous system involving also the heart (senso-cardial reflex) and skin (senso-cutaneous reflex), as well as other organs and systems of the human body.

Soviet Scientist Antifascist Committee,

Moscow. (Recd. by cable, Oct.12)

\section{Glucose Excretion by the Rabbit Kidney}

Work carried out in this laboratory has proved ${ }^{1}$ that the glucose threshold in the rabbit kidney is stabilized in the neighbourhood of a plasma concentration $\left(C_{b}\right)$ of $240 \mathrm{mgm}$. per $100 \mathrm{mil}$. plasma (mgm. per cent) when the animal is under the influence of urethane. In a few rabbits the threshold level under urethane was higher than $300 \mathrm{mgm}$. per cent, but the bulk of the observations fell between 200 and 260 , with a marked modal peak at $240 \mathrm{mgm}$. per cent. Large doses of insulin-approximately 10 units/kgm. - had a doubtful effect on the urethane threshold level, depressing the mean threshold from 282 to 243 , which is not a significant change. More recent work ${ }^{2}$ has shown that under nembutal narcosis, insulin, 1 unit $/ \mathrm{kgm}$., develops a marked depressant effect on the threshold level, and may indeed cause a rise in urine glucose, measured as fermentable reducing substance, at a time when $C_{b}$ is falling.

It will be noted that the dose of insulin necessary to lower the threshold in the rabbit under nembutal narcosis is approximately one tenth the dose which in the urethanized rabbit produced a minimal effect.
This indicates that urethane inhibits some of the effects of insulin, and the implications of this discovery are discussed in a recent publication ${ }^{2}$.

Adrenalin causes a marked rise of threshold in the rabbit both under urethane and nembutal narcosis ${ }^{2}$. The threshold in the unanæsthetized rabbit is in the neighbourhood of $C_{b}=120 \mathrm{mgm}$. per cent. Unpublished results on normal young men show that the insulin effect may be elicited sometimes. The adrenalin effect has been shown to occur in renal glycosuria.

The investigation is continuing.

T. W. T. DILLON.

Dept. Materia Medica and Therapentics, University College,

Dublin. Oct. 5.

'Dillon and O'Donnell, Proc. Roy. Irish Acad., 42, B, 14, 365.

${ }^{2}$ Dillon and Feric, Proc. Roy. Irish Acad., 47, B, 7, 179.

\section{Records of Lancashire Cetacea}

As records of Lancashire cetaceans are few, I thought it worth recording that when told of a 'big porpoise' washed up on the west Lancashire coast at Birkdale, Southport, on September 23, 1942, I identified it as a young male bottle-nosed dolphin (Tursiops truncatus Montagu) and took the following measurements : length 105 in., flippers 14 in., tail flukes 21 in. across, girth of body 50 in., depth of body 22 in., 'bottle nose' extension of upper jaw 5 in., 22 pairs of teeth in upper jaw, and probably same in lower but a few were removed by souvenirhunters. Upper parts black, also flippers; underparts pale grey. The only previous Lancashire record I can trace was a specimen stranded at Walney Island on August 8, 1917'.

On December 10, 1939, when a reported 'killer whale' was stranded alive by the flood tide on the Mersey bridge pontoons at Widnes, I was surprised to find that no one had gone to investigate it, and when I got there it had been cut up and returned to the river, but I obtained sufficient press photographs to identify it as Risso's grampus (Grampus griseus) and sent a photographic print to the Liverpool Museum, which was later sent to the British Museum. I also obtained a film strip of Leica negative of various positions of the specimen and sent this in to Liverpool Museum to authenticate the record, but unfortunately a year later, when the Museum was burned in an air raid, these negatives had not been developed and they were lost in the fire. Measurements and details I secured at the time from those who killed the specimen at Widnes, and from the photographs, were: length $11 \frac{1}{2} \mathrm{ft}$., no teeth in upper jaw, a few teeth in lower jaw $\frac{3}{4}$ in. apart and blunt; body marbled and streaked with greyish-white, underparts smooth; long, narrow, white flippers; tail flukes long and narrow; dorsal fin tall; white about the muzzle; lower jaw shorter than upper jaw. Total weight about two hundredweights. It was alive and 'blowing' when caught by the men. A recognizable photograph appeared in the Liverpool Post and other local papers. There is no previous Lancashire record, but in the north-west area one was recorded at Bardsey in 1933 and there is a much older Solway record. Eric Hardy.

British Empire Naturalists' Association, (Merseyside Branch),

47 Woodsorrel Road, Liverpool, 15.

1 Booth, Naturalist, 300 (1917). 